http://jmscr.igmpublication.org/home/ ISSN (e)-2347-176x ISSN (p) 2455-0450

crossref DOI: https://dx.doi.org/10.18535/jmscr/v8i3.49

Journal Of Medical Science And Clinical Research

\title{
Role of Multidetector CT in Evaluation of Paranasal Sinus Pathologies with Histopathology Correlation
}

\author{
Authors \\ Murali $^{1 *}$, Sathish Babu ${ }^{2}$, Jagadeep ${ }^{3}$ \\ ${ }^{1}$ Radiology Resident, Sree Mookambika Institute of Medical Sciences, Kanyakumari \\ ${ }^{2}$ Professor, Department of Radiodiagnosis, Sree Mookambika Institute of Medical Sciences Kanyakumari \\ ${ }^{3}$ Assistant Professor, Department of Radiodiagnosis, Sree Mookambika Institute of Medical Sciences, \\ Kanyakumari \\ *Corresponding Author \\ Dr R.Murali \\ Junior Resident, Department of Radiodiagnosis, Sree Mookambika Institute of Medical Sciences, \\ Kulasekharam, Kanyakumari, India
}

\begin{abstract}
Background: Paranasal sinus diseases include a wide spectrum of conditions including inflammatory, non-neoplastic and neoplastic causes with a reported incidence of 1 to $4 \%$ of the population

Aims \& Objectives: To assess the role of CT in evaluation of inflammatory sinonasal diseases

Materials and Methods: All Patients referred from Department of Otorhinolaryngology for Paranasal Sinus CT to the Department of Radio diagnosis From December 2017 to October 2019

Results: Sinusitis is the most common pathology detected on CT and on final pathological diagnosis followed by polyp.Acute/chronic sinusitis $-100 \%$ sensitivity and $79.6 \%$ specificity. Polyps - sensitivity of $70.4 \%$ and specificity of $98.2 \%$. Fungal sinusitis- sensitivity of $83.3 \%$ and specificity of $100 \%$. Mucocele and rhinosporidiosis was diagnosed with $100 \%$ accuracy. Inverted papilloma and carcinoma (poorly differentiated)- specificity $100 \%$ for both, sensitivity $66.7 \%$ and $75 \%$ respectively.

Conclusion: Pathological diagnosis correlated well with the CT diagnosis, proving that it is an ideal modality to evaluate sinonasal pathologies.
\end{abstract}

\section{Introduction}

Sinonasal imaging has progressed in an orderly fashion as each generation of imaging modality has advanced gradually on domain of the former generation. ${ }^{[1]}$ Paranasal sinus diseases include a wide spectrum of conditions including inflammatory, non-neoplastic and neoplastic causes with a reported incidence of 1 to $4 \%$ of the population. The radiological evaluation of sinonasal diseases is very essential as the clinical findings in these cases may be non-specific. ${ }^{[2,3]}$ The role of imaging is to document the extent of disease, to answer questions regarding ambiguous cases, and to provide an accurate display of the anatomy of the sinonasal system. The plain films are no longer considered to be a part of the primary imaging armamentarium as they give only an outline of the anatomy and underlying pathology ${ }^{[4]}$. CT has become the investigation of choice for radiological diagnosis of nasal and 
sinus diseases Computerized tomography (CT) is considered the gold standard for preoperative evaluation of PNS diseases for appropriate patient selection before functional endoscopic sinus surgery (FESS) - providing a "ROAD MAP" for the surgeon $^{[5]}$ MDCT can show anatomic structures that are not visualised by physical examination or diagnostic nasal endoscopy and is, hence, the study of choice for the surgeon who is considering functional endoscopic sinus surgery ${ }^{[6]}$ CT is best at defining the complex sinonasal anatomy and anatomic variations that are inaccessible by physical examination or endoscopy because of its 3D high resolution ${ }^{[7]}$.

\section{Aims \& Objectives}

1) To assess the role of CT in evaluation of inflammatory sinonasal diseases by evaluating the sensitivity and specificity of CT in diagnosis of various inflammatory sinonasal diseases with histopathology correlation

2) To study prevalence and pattern of sinusitis in the studied population

\section{Materials and Methods}

Study Design

Cross Sectional Design-Diagnostic test evaluation.

Study Setting

Department of Radio diagnosis - Sree Mookambika institute of Medical Sciences

\section{Study Period}

From December 2017 to October 2019

\section{Study Subjects}

All Patients referred from Department of Otorhinolaryngology for Paranasal Sinus CT to the Department of Radio diagnosis, in the specified time period.

\section{Inclusion Criteria}

All patients referred from Department of Otorhinolaryngology for CT Paranasal sinus with follow-up histopathological confirmation from our institution, who will consent for the study.

\section{Exclusion Criteria}

All cases of trauma.

Inadequate CT evaluation.

Study sample size: 82

\section{Results and Discussion}

Sinusitis is the most common pathology detected on CT and on final pathological diagnosis followed by polyp.

The most common sinus involved was maxillary sinus and the commonest pattern of inflammation was sinonasal polyposis followed by osteomeatal unit pattern

Correlating CT diagnosis with final diagnosis,

Acute/chronic sinusitis $-100 \%$ sensitivity and 79.6 $\%$ specificity.

Polyps - sensitivity of $70.4 \%$ and specificity of 98.2\%.

Fungal sinusitis- sensitivity of $83.3 \%$ and specificity of $100 \%$.

Mucocele and rhinosporidiosis was diagnosed with $100 \%$ accuracy.

Inverted papilloma and carcinoma (poorly differentiated)- specificity $100 \%$ for both, sensitivity $66.7 \%$ and $75 \%$ respectively.

\section{Sinonasal Patterns of Inflammation}

Infundibular pattern in $7(9.6 \%)$

OMU pattern in $19(26 \%)$

SER pattern in $10(13.7 \%)$

Sinonasal polyposis pattern in $25(34.2 \%)$

Sporadic or unclassifiable pattern in $12(16.4 \%)$ 


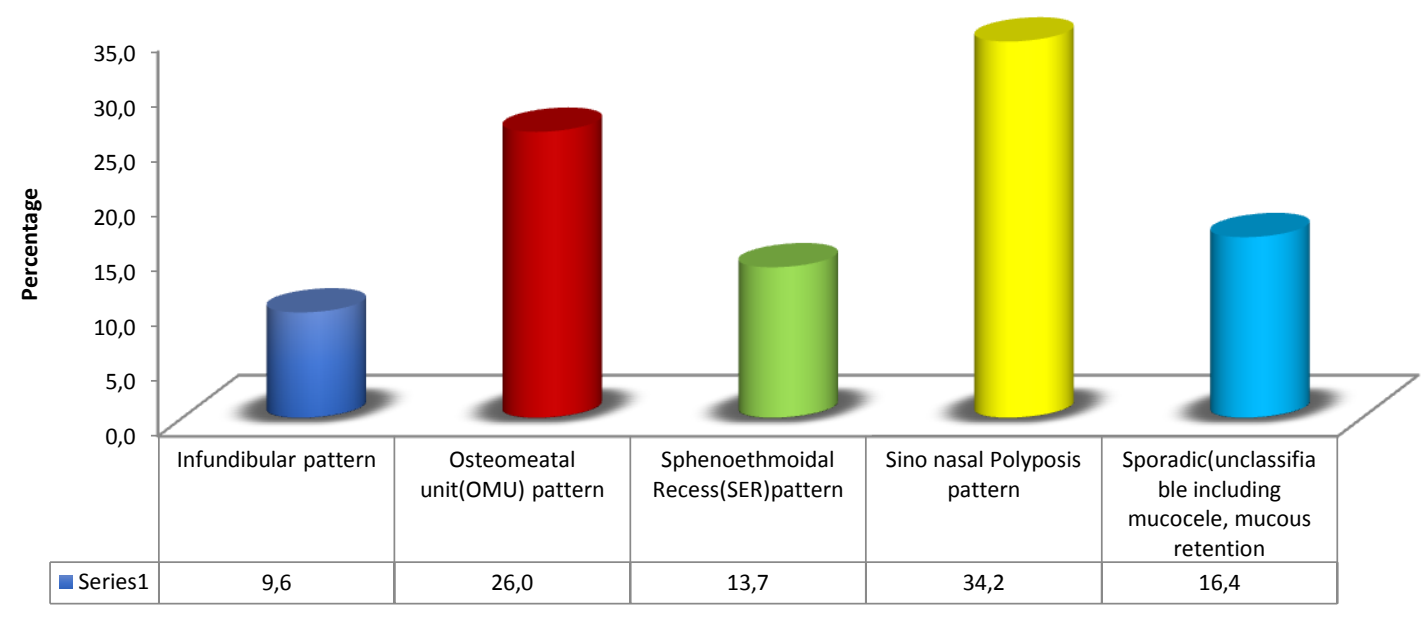

\section{Case 1- Squamous Cell Carcinoma}

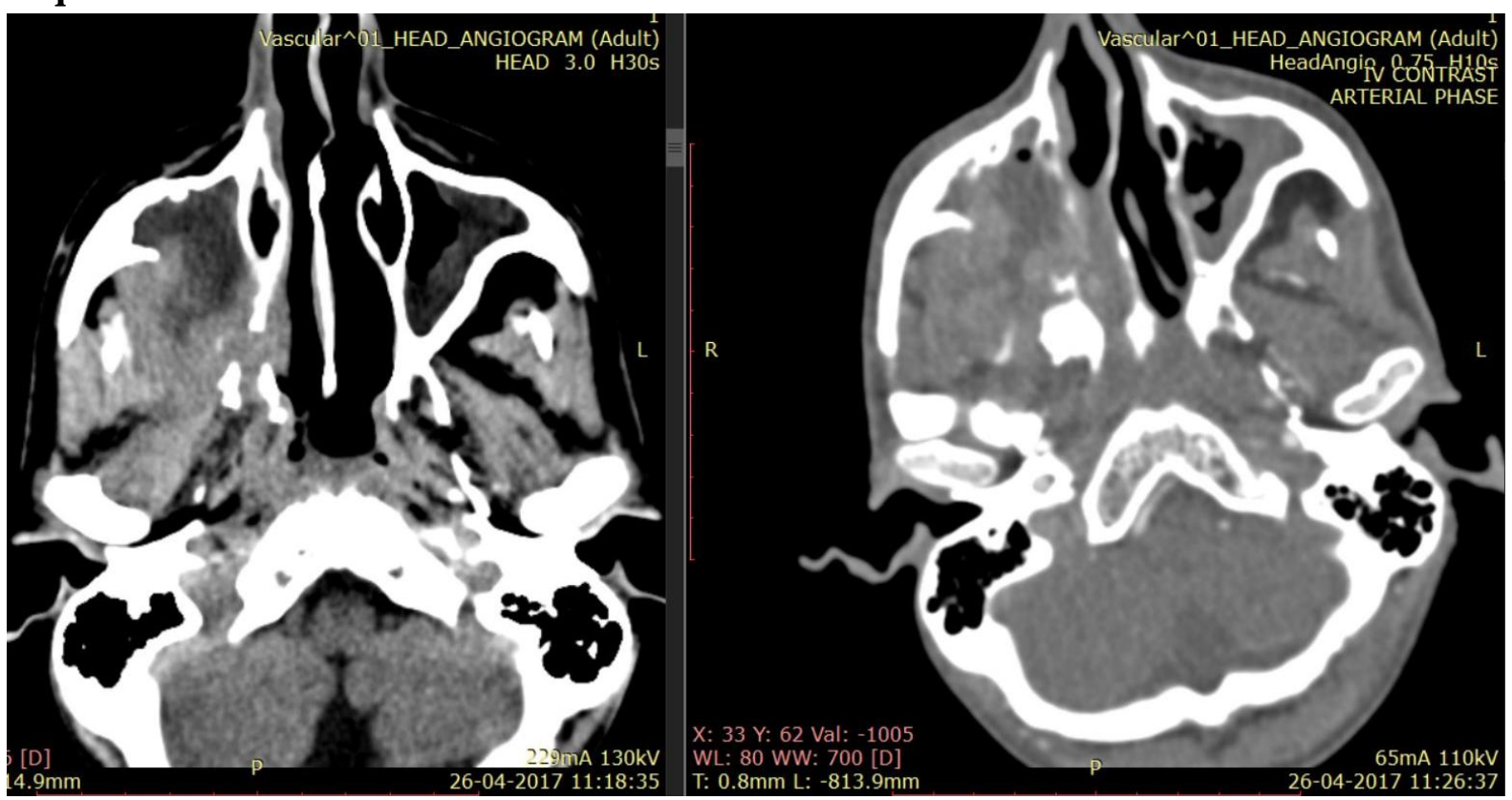

CT plain and post contrast study showing enhancing soft tissue density mass in right maxillary sinus with extension into infratemporal fossa, pterygopalatine fossa, orbit and sphenoid sinus 


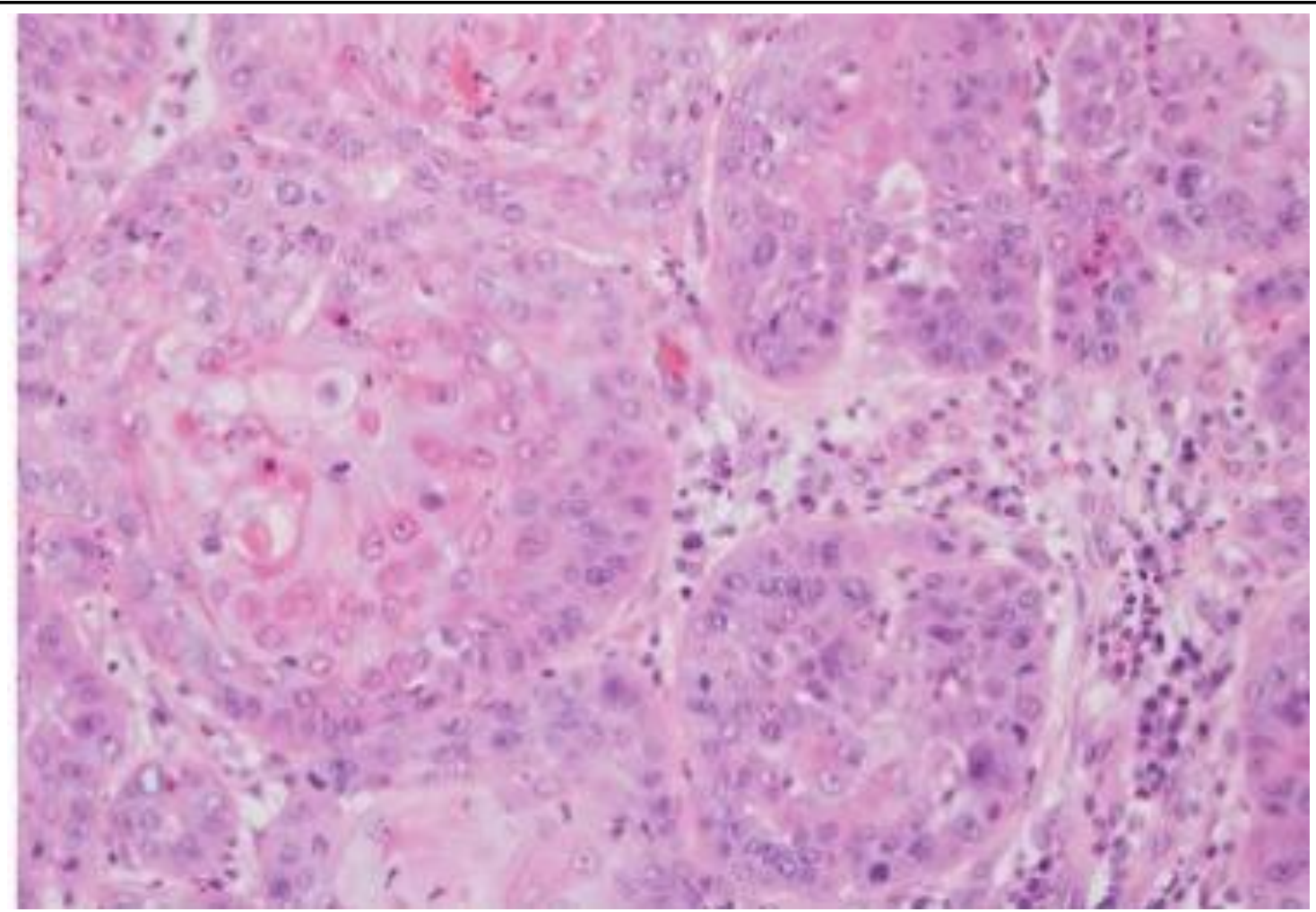

Photomicrograph - High power view showing cells with abundant eosinophilic cytoplasm and foci of keratinization

Case 2- Right Frontoethmoidal Inverted Papilloma

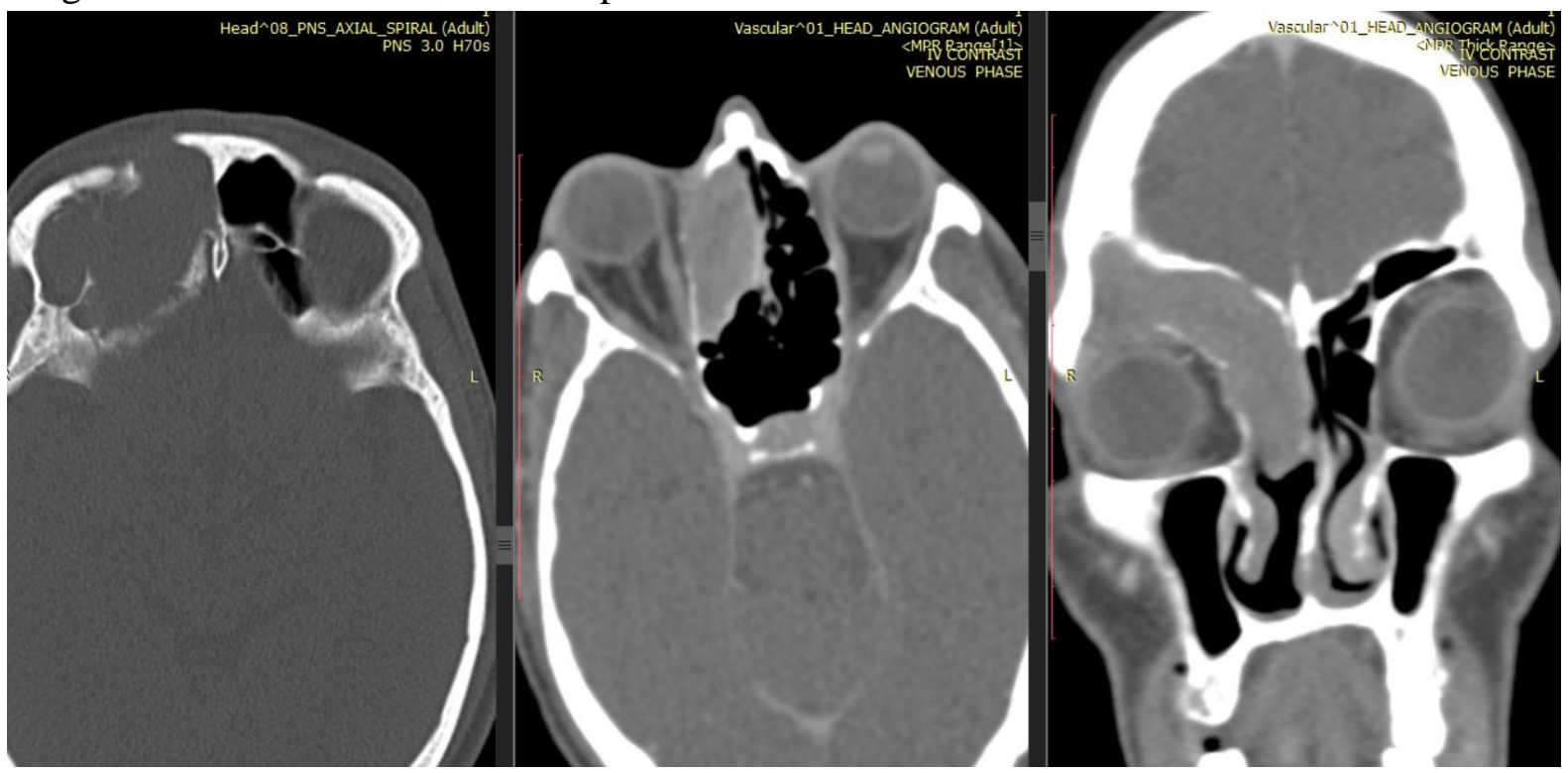

CT plain and post contrast study showing homogenously enhancing soft tissue density lesion causing expansion of the sinus and widening of ipsilateral frontoethmoidal recess and extending into middle meatus. Orbital involvement with destruction of superior and medial walls of orbit. 

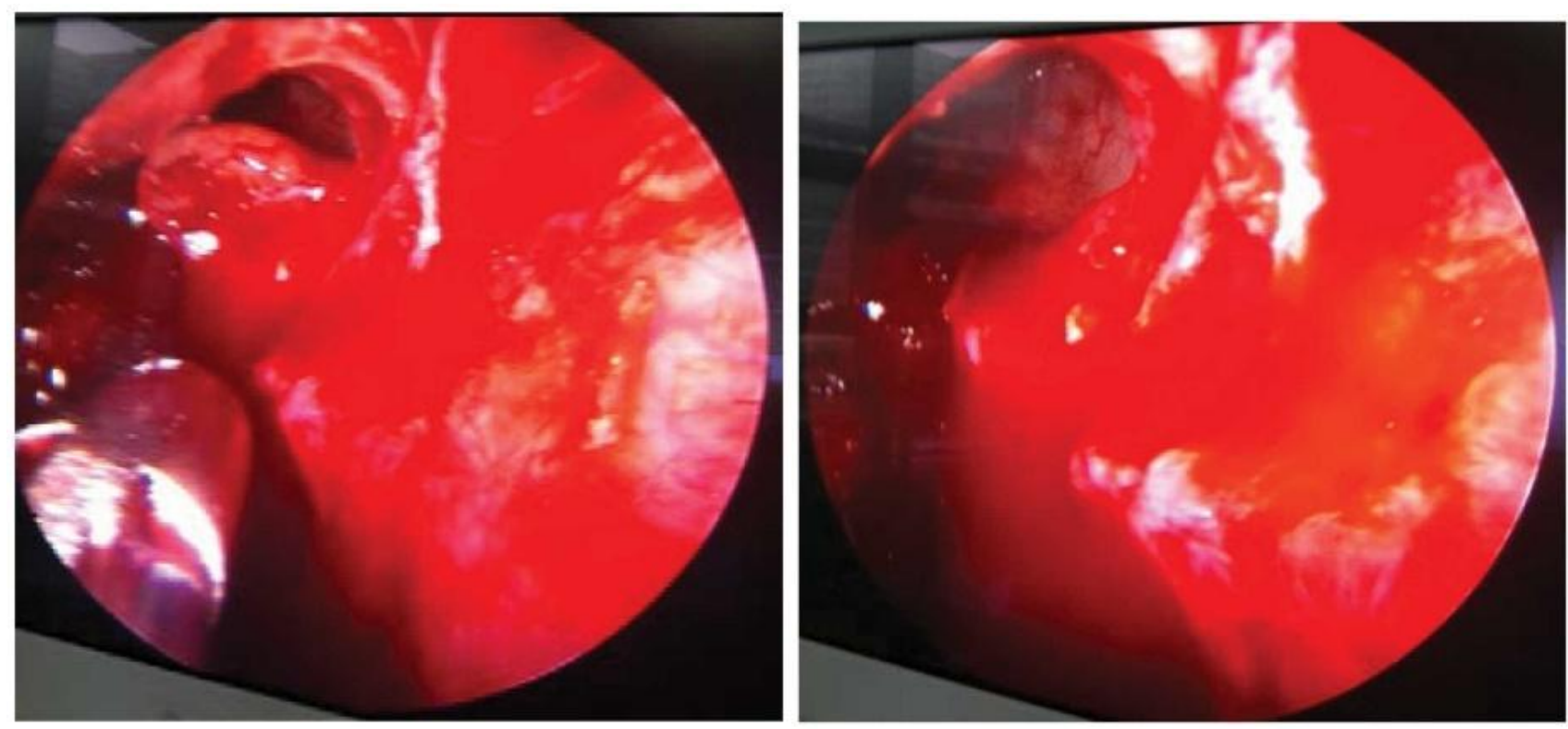

Endoscopic view of inverted papilloma of frontal sinus-intraoperative and postoperative images

\section{Conclusion}

In conclusion, pathological diagnosis correlated well with the CT diagnosis, proving that it is an ideal modality to evaluate sinonasal pathologies. This study thus proves that $\mathrm{CT}$ is an excellent imaging modality for evaluating the normal anatomy, variants, pathologies and associated complications of the paranasal sinuses thus helping the planning and further management of the patient.

\section{References}

1. Yousem DM. Imaging of sinonasal inflammatory disease. Radiology. 1993;188(2):303- 14.

2. Zinreich JS. Functional anatomy and Computed Tomography imaging of the paranasal sinuses. The American Journal of the Medical Sciences. 1998;316(1):212.

3. Mafee MF. Endoscopic sinus surgery: Role of the Radiologist. AJNR Am J Neuroradiol. 1991;12(5):855-60.
4. Fatterpekar G, Delman B, Som P. Imaging the paranasal sinuses: Where we are and where we are going. Anat Rec. 2008; 291(11):1564-72.

5. Zinreich S. Rhinosinusitis: Radiologic diagnosis. Otolaryngology - Head and Neck Surgery. 1997;117(3):27-34.

6. Miller JC. Imaging for Sinusitis. Radiology Rounds A Newsletter for Referring Physicians Massachusetts General Hospital Department of Radiology. 2009;7(8).

7. Momeni AK, Roberts CC, Chew FS. Imaging of chronic and exotic sinonasal disease: Review. AJR. 2007;189:S35-S45. 